Supporting Information for:

\title{
Performance and Mechanisms of PropS-SH/HA Coatings in the Inhibition of Pyrite Oxidation
}

\author{
Shuang Yang ${ }^{1,2,3}$, Tianlie Luo ${ }^{1,2,3 *}$, Jiajun Fan ${ }^{1,2,3}$, Chengzhi Zhou ${ }^{4}$, \\ Mengyao $\mathrm{Hu}^{1,2,3}$, Jinyu Wang ${ }^{1,2,3}$, Lijia Wen ${ }^{1,2,3}$, Li Qin ${ }^{1,2,3}$, Guo Liu' ${ }^{1,2,3 *}$
}

1 State Key Laboratory of Geohazard Prevention and Geoenvironment Protection, Chengdu University of Technology, Chengdu 610059, People's Republic of China

2 State Environmental Protection Key Laboratory of Synergetic Control and Joint Remediation for Soil \& Water Pollution, Chengdu University of Technology, Chengdu 610059, People's Republic of China

3 College of Ecology and Environment, Chengdu University of Technology, Chengdu 610059, People's Republic of China

${ }^{4}$ Qingdao Engineering Research Center for Rural Environment, College of Resource and Environment, Qingdao Agricultural University, Qingdao 266109, People's Republic of China

\section{Corresponding Authors}

*Tianlie Luo, E-mail: luotianlie19@dlut.edu.cn

* Guo Liu, E-mail: liuguo@cdut.cn

Number of pages: 2; Number of tables:1; Number of figures: 2

\section{Contents}

Tab. S1 Chemical properties of the sampled mine gushing water. . .1

Fig.S1 Installation diagram of columnar leaching experiment . .2

Fig. S2. Changes of $\mathrm{pH}$ in the leaching solution during the columnar leaching experiment..2 
Table S1. Chemical properties of the sampled mine gushing water.

\begin{tabular}{cccccc}
\hline $\mathrm{pH}$ & $\mathrm{Mn}(\mathrm{mg} / \mathrm{L})$ & $\mathrm{Cd}(\mathrm{mg} / \mathrm{L})$ & $\mathrm{SO}_{4}{ }^{2-}(\mathrm{mg} / \mathrm{L})$ & $\mathrm{T}-\mathrm{Fe}(\mathrm{mg} / \mathrm{L})$ & $\mathrm{DO}(\mathrm{mg} / \mathrm{L})$ \\
\hline 6.17 & 1.05 & 68.6 & 699 & 36.3 & 7.37 \\
\hline
\end{tabular}

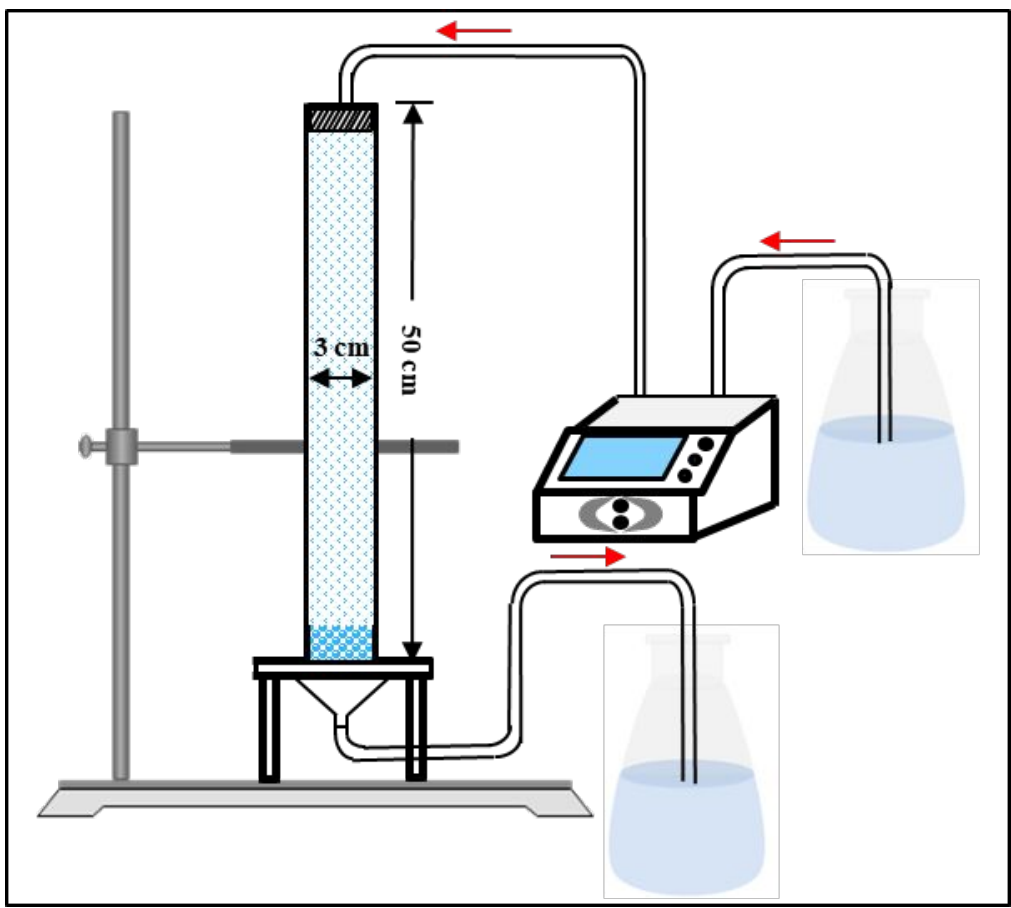

Figure S1. Installation diagram of columnar leaching experiment

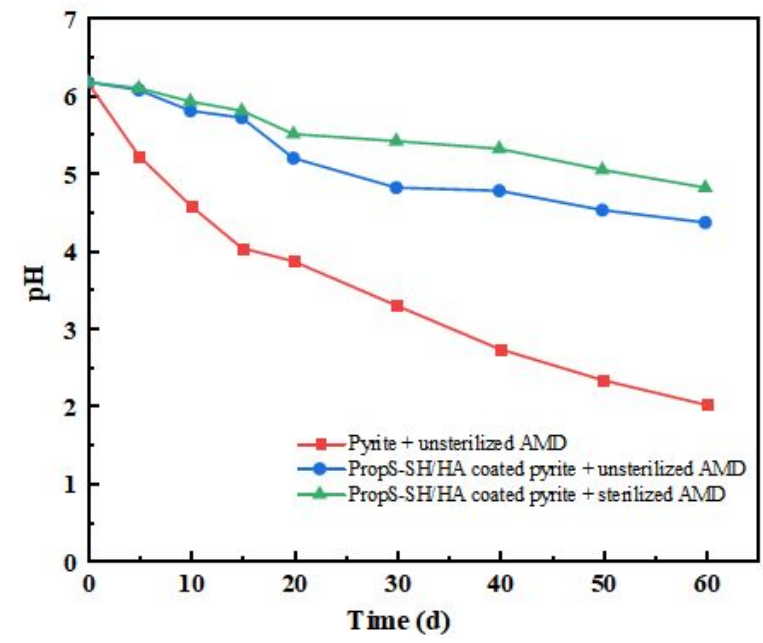

Figure S2. Changes of $\mathrm{pH}$ in the leaching solution during the columnar leaching experiment 